\title{
Robust Enkephalin Innervation of the Locus Coeruleus from the Rostral Medulla
}

\author{
Guy Drolet, ${ }^{a}$ Elisabeth J. Van Bockstaele, and Gary Aston-Jones \\ Division of Behavioral Neurobiology, Department of Mental Health Sciences, Hahnemann University, Philadelphia, \\ Pennsylvania 19102- $\uparrow 192$
}

Substantial evidence indicates that the noradrenergic nucleus locus coeruleus (LC) is a key target of endogenous opioid neurons, and an important structure in mediating opiate effects. However, the detailed distribution of opioid fibers and terminals in the LC, and the sources of its opioid innervation are unknown. In the present study, the enkephalin innervation of the LC was investigated in the rat using an antibody directed against the extended enkephalin peptide Met-enkephalin-Arg ${ }^{6}$-Gly ${ }^{7}$-Leu' (ENK), which is derived exclusively from the enkephalin precursor proenkephalin A. An antibody directed against tyrosine hydroxylase (TH), the synthetic enzyme for catecholaminergic neurons, was also applied to the same tissue sections to delineate LC neurons and their dendrites.

Enkephalin fibers in the LC were dense and highly varicose. In horizontal sections, ENK-like-immunoreactive (ENKir) fibers of considerable length coursed throughout the rostrocaudal orientation of the LC proper, whereas in frontal sections ENK-ir processes appeared punctate, suggesting a rostrocaudal orientation. Dense ENK-ir fibers were also identified in the rostromedial and caudal juxtaependymal pericoerulear regions where extranuclear dendrites of LC neurons are extensive.

As previously reported, there were no ENK-ir neurons in the LC nucleus proper, but such cells were present in neighboring structures such as the parabrachial, sphenoid, and Barrington's nuclei as well as in the central gray and in the subcoeruleus area. ENK-ir neurons were also present in nuclei of the rostral medulla reported to be major afferents of the LC, the nucleus prepositus hypoglossi (PrH), and the nucleus paragigantocellularis (PGi). In the dorsomedial medulla, numerous ENK-ir neurons were identified in the medial aspect of the PrH and along the medial longitudinal fasciculus in the perifascicular reticular formation. In the ventrolateral medulla, ENK-ir neurons were distributed in a conical caudorostral column throughout the PGi.

Retrograde transport of a WGA-colloidal gold conjugate

\footnotetext{
Received Nov. 7, 1991; revised Mar. 10, 1992, accepted Mar. 17, 1992.

We thank Dr. Hideo Akaoka and Dr. David A. Morilak for helpful discussions. This work was supported by U.S. Public Health Service Grants NS 24698 and DA 06214. G.D. had a fellowship from Le Fonds en Recherche en Santé du Québec.

Correspondence should be addressed to Dr. Gary Aston-Jones, Department of Mental Health Sciences, Hahnemann University, M.S. 403, Broad and Vine Street, Philadelphia, PA 19102

aPresent address: Centre Hospitalier de L'Université Laval, Unité de Recherche sur l'Hypertension, 2705 Boulevard Laurier, Ste-Foy, Quebec, Canada, G1 V 4G2. Copyright (C) 1992 Society for Neuroscience 0270-6474/92/123162-13\$05.00/0
}

(WGA-apoHRP-Au) from LC, combined with immunohistochemistry for ENK in the same tissue sections, revealed that LC afferents in the PGi and PrH were interdigitated with ENKir neurons. Furthermore, an unexpectedly high incidence of doubly labeled neurons were identified in both PGi and PrH. Overall, $57 \%$ and $56 \%$ of the LC-projecting neurons in PGi and $\mathrm{PrH}$, respectively, were also immunoreactive for ENK, suggesting that enkephalinergic neurons of PGi and PrH are major afferents to noradrenergic LC neurons.

Substantial evidence indicates that locus coeruleus (LC) neurons receive endogenous opioid inputs. (1) The nucleus LC contains a high concentration of opioid receptors, particularly of the $\mu$ and $\kappa$-subtypes (Pert et al., 1975; Atweh and Kuhar, 1977; Tempel and Zukin, 1987). (2) Local application of morphine or of the endogenous opioid peptide enkephalin (ENK) inhibits the spontaneous activity of LC neurons through activation of $\mu$-opioid reccptors and hyperpolarization with increased potassium conductance (Bird and Kuhar, 1977; Young et al., 1977; North and Williams, 1985; Aghajanian and Wang, 1987). In addition, acute morphine administration decreases the turnover of norepinephrine (NE) in LC target areas (Montel et al., 1974; Arbilla and Langer, 1978). Other evidence indicates a presynaptic inhibitory role for $\kappa$-opioid receptors in LC (McFadzean et al., 1987). (3) In anatomical studies, each class of endogenous opioids has been reported to innervate the $\mathrm{LC}$ region, including enkephalin (Simantov et al., 1977; Sar et al., 1978; Pickel et al., 1979; Uhl et al., 1979; Finley et al., 1981a; Watson et al., 1982; Khachaturian et al., 1983; Williams and Dockray, 1983; Petrusz et al., 1985; Fallon and Leslie, 1986; Murakami et al., 1987), $\beta$-endorphin (Bloom et al., 1978; Finley et al., 1981 b; Ibuki et al., 1989), and dynorphin (Watson et al., 1982; Fallon and Leslie, 1986; Ibuki et al., 1989). In addition, electron microscopic studies have shown that enkcphalin-like-immunoreactive (ENKir) axon terminals form asymmetric axodendritic synapses with LC neurons labeled for tyrosine hydroxylase (TH), a specific marker for catecholaminergic neurons (Pickel et al., 1979).

Although the above evidence indicates that opioid neurons may be substantial afferents to the $L C$, the anatomical substrates of opioid innervation of the LC have not been established. In particular, there is little detailed information on the distribution of opioid fibers and terminals in the LC nucleus and pericoerulear regions containing LC dendrites. Moreover, the origin(s) of the opioid input to LC is not known. Previous studies from this laboratory revealed that major sources of afferents to the LC are found in the nucleus paragigantocellularis (PGi) in the rostral ventrolateral medulla and in the medial nucleus prepositus hy- 
poglossi $(\mathrm{PrH})$ in the dorsomedial rostral medulla (Aston-Jones et al., 1986, 1991). Studies by others have reported opioid neurons in both of these regions (Finley et al., 1981a; Khachaturian et al., 1983; Williams and Dockray, 1983; Ménétrey and Basbaum, 1987; Murakami et al., 1987, 1989; Sasek and Helke, 1989).

As ENK is the most concentrated endogenous opioid in the LC (Zamir et al., 1984), and has pronounced effects on LC physiology (Akil et al., 1984; North and Williams, 1985; Williams et al., 1987; Johnson and Fleming, 1990), we began our investigation of opioid innervation of the rat $\mathrm{LC}$ by examining (1) the distribution and the density of ENK-ir fibers in the LC and peri-LC area, and (2) determining the source of enkephalin afferents to the LC nucleus.

\section{Materials and Methods}

Male Sprague-Dawley rats (Taconic Farms; $300-350 \mathrm{gm}$ ) were deeply anesthetized with chloral hydrate ( $400 \mathrm{mg}$, i.p.) and placed in a stereotaxic apparatus for surgery. Anesthesia was maintained throughout the surgical procedure by administering supplemental doses of chloral hydrate $(100 \mathrm{mg} / \mathrm{kg})$ every hour. Body temperature was maintained at $37^{\circ}$ with a feedback-controlled heating pad.

Injection placements. The snout was lowered to position bregma 2 $\mathrm{mm}$ below lambda, a scalp incision was made, and a hole was drilled in the skull over LC (3.8 mm caudal to lambda and $1.2 \mathrm{~mm}$ lateral to the midline). Glass micropipettes (Omega dot, Glass Co. of America; tips of 8-10 $\mu \mathrm{m}$ diameter) were filled with a solution of wheat germ agglutinin conjugated to inactive horseradish peroxidase and coupled to $15 \mathrm{~nm}$ colloidal gold particles (WGA-apoHRP-Au), synthesized according to Basbaum and Ménétrey (1987). The solution of WGAapoHRP-Au was diluted in $0.9 \%$ sodium chloride $(1: 1 \mathrm{v} / \mathrm{v})$ before filling the pipette, to aid in recordings. Extracellular recordings of LC neuronal activity obtaincd through the injection pipette were used to identify LC tentatively by its characteristic discharge properties, including slow, tonic spontaneous discharge $(1-5 \mathrm{~Hz})$ and biphasic excitatory-inhibitory responses to tail pinch (Aghajanian, 1978; Ennis and Aston-Jones, 1988). Once the LC was localized, the silver wire that had transmitted the electrophysiological signal was removed from the pipette, which was then connected via tubing to a solenoid-controlled pneumatic pressure device (Picospritzer, General Valve Corp.). Volumes of 150-300 $\mathrm{nl}$ of WGA-apoHRP-Au were ejected from the pipette by air pressure pulses over a $30 \mathrm{~min}$ period (approximately $20 \mathrm{psi}, 200-250 \mathrm{msec}$ pulses, 0.5 pulses/sec). The pipettes were positioned at the injection site for 10-15 min before and after depositing the tracer. The injected volume was monitored by measuring the movement of the fluid-air meniscus in the pipette lumen ( $50 \mathrm{nl}$ accuracy). Following the surgery, a broad-spectrum antibiotic (suspension of benzathine penicillin $G$ and penicillin $G$ procaine, 30,000 U, s.c.) was administered and the animals were caged individually. Following a 3-7 d survival time, animals were again deeply anesthetized with chloral hydrate $(400 \mathrm{mg} / \mathrm{kg}$, i.p.) and injections of colchicine (Sigma) were made stereotaxically into the lateral ventricles ( $50 \mu \mathrm{g}$ in $5 \mu \mathrm{l}$ of saline, per ventricle).

Immunohistochemistry. Animals were allowed to survive $20-24 \mathrm{hr}$ following colchicine injections, and were then deeply anesthetized with Nembutal $(65 \mathrm{mg} / \mathrm{kg}$, i.p.) and perfused transcardially with $200 \mathrm{ml}$ of oxygenated tissue culture medium (Dulbecco's Modified Eagle's Medium:Ham's F12, 1:1; Sigma) at $4^{\circ} \mathrm{C}(\mathrm{pH} 7.4)$. This prerinse was followed immediately by $1000 \mathrm{ml}$ of $4 \%$ paraformaldehyde in $0.1 \mathrm{M}$ phosphate buffer $(\mathrm{PB})\left(4^{\circ} \mathrm{C}, \mathrm{pH} 7.4\right)$. Brains were blocked and placed in this same fixative for $90 \mathrm{~min}$. After this postfixation, brains were cryoprotected by immersion in $20 \%$ sucrose overnight at $4^{\circ} \mathrm{C}$.

For retrograde transport combined with immunohistochemistry of ENK-ir somata, 40- $\mu$ m-thick frozen sections of colchicine-treated animals were cut on a cryostat (Microm, Zeiss Corp.) and collected into 0.1 M PB (pH 7.4). Generally for each brain, two or three out of four sections were used for staining enkephalin peptides, and one of four sections was stained for Nissl and retrograde labeling only. The sections were rinsed three times $(15 \mathrm{~min}$ each) in $0.1 \mathrm{M}$ sodium acetate $(\mathrm{pH}$ 5.5), and the colloidal gold tracer was silver-intensified using a commercially available silver enhancement kit (Amersham) for 30 min. In brief, sections were rinsed three times in $0.1 \mathrm{M}$ citrate buffer $(\mathrm{pH}=5.5)$ and incubated with the initiator and enhancer of the kit for $30 \mathrm{~min}$ under low illumination. Sections were then rinsed in sodium acetate buffer twice and the silver was fixed with $2.5 \%$ sodium thiosulfate in $0.1 \mathrm{M}$ PB solution for $5 \mathrm{~min}$. This procedure enabled the visualization of the retrogradely transported colloidal gold conjugate, which appeared as black punctate granules in neuronal perikarya and dendrites.

Sections containing WGA-apoHRP-Au were subsequently processed for enkephalin-like immunoreactivity using the antibody directed against the extended enkephalin (FNK; 1:8000, described below). In some animals we also used an antibody directed against met-enkephalin (rabbit anti-met-enkephalin, 1:2000-1:4000; IncStar). The primary antisera were localized with biotinylated goat anti-rabbit antibody $(1: 200$ or $1: 400)$ and the avidin-biotin peroxidase complex (1:400; Vector Laboratories). The avidin-biotin peroxidase complex was visualized using a solution of diaminobenzidine $\left(0.04 \%\right.$; Sigma) and $\mathrm{H}_{2} \mathrm{O}_{2}(0.003 \%)$. Sections were then mounted on gelatinized slides.

Experiments using antibodies for both enkephalin and the catecholamine-synthesizing enzyme tyrosine hydroxylase $(\mathrm{TH})$ were conducted to examine the pattern of enkephalin innervation of TH-immunoreactive (TH-ir) cells and dendrites in non-colchicine-treated animals. For enkephalin immunoreactivity, we used an antibody directed against the extended ENK (Met-enkephalin-Arg ${ }^{6}-\mathrm{Gly}^{7}-\mathrm{Leu}^{8}$; antibody kindly provided by Dr. Eckard Weber, University of California at Irvine). This extended enkephalin is derived exclusively from proenkephalin $A$, the precursor for met- and leu-enkephalin, and is thus a specific marker for enkephalin-expressing neurons (Kilpatrick ct al., 1981; Comb ct al., 1982). This rabbit antibody was used at a dilution of 1:8000, which was previously determined by titration in a pilot study. Fourteen-micronthick frozen sections were cut in the horizontal plane and mounted directly onto gelatinized slides. The sections were incubated in a cocktail of primary antisera (ENK, 1:8000, described above, and TH, 1:1000, mouse monoclonal; IncStar) and subsequently treated with affinity-purified secondary antibodies to visualize both antigens [donkey antimouse conjugated to fluorescein isothiocyanate (FITC) and goat antirabbit conjugated to rhodamine isothiocyanate (RITC) for TH and ENK, respectively, both at a dilution of 1:100; Jackson Labs]. Although these antibodies have been well characterized (Weber et al., 1982; Fallon and Leslie, 1986; Ménétrey and Basbaum, 1987), staining with them will be referred to as TH-like immunoreactivity (TH-ir) and ENK-like immunoreactivity (ENK-ir) as it is possible that other antigens exist in brain that would be recognized by these antibodies.

Data analysis. In material from non-colchicine-treated animals stained with fluorescent antibodies for ENK-ir fibers and TH-ir somata within the LC, sections were visualized and photographed using epifluorescence microscopy on a Leitz Aristoplan microscope. TH was visualized with red illumination (FITC; $490 \mathrm{~nm}$ peak emission) and ENK with green illumination (RITC; $540 \mathrm{~nm}$ peak emission). Photographs were taken on the same microscope with Kodak TMax film (ASA 100 or 400).

For retrograde labeling combined with immunohistochemistry for ENK somata in colchicine-treated rats, sections were examined under low- and high-power bright-field microscopy for double labeling. Retrogradely labeled neurons were identified by accumulation of black particles (revealed after silver intensification, described above) in their perikarya and proximal dendrites. A criterion of at least 10 particles within a soma-dendritic profile was used to identify retrogradely labeled neurons. Immunoreactivity for enkephalin appeared as a diffuse brown reaction product that was clearly distinguishable from the dense black particles of the WGA-apoHRP-Au. Doubly labeled cells contained both black granules and homogeneous brown immunoperoxidase reaction product, indicating retrograde transport of WGA-apoHRP-Au and ENKir, respectively. Neurons were counted only if somatic profiles included the nucleolus or dendritic processes, and were at least $5 \mu \mathrm{m}$ in diameter. For one animal, a second independent observer repeated the counting procedure, which yielded similar results.

Labeled neurons were counted in sections throughout the PGi and PrH regions (approximately 12 sections/animal, $120 \mu \mathrm{m}$ apart). The PGi, as described for the rat (Andrezik et al., 1981), extends from the anterior pole of the lateral reticular nucleus to the level of the caudal third of the facial nucleus. We arbitrarily divided the PGi into three rostrocaudal levels, with each level extending about $700 \mu \mathrm{m}$ rostrocaudally. The juxtafacial PGi constitutes the rostral end of the nucleus, located between the facial nucleus and the pyramidal tract and nucleus gigantocellularis pars alpha (corresponding to plates $62-63$ of the rat brain atlas by Paxinos and Watson, 1986). The mid, or retrofacial, PGi (plates 64-67), and the caudal PGi (plates 68-70) are located more 


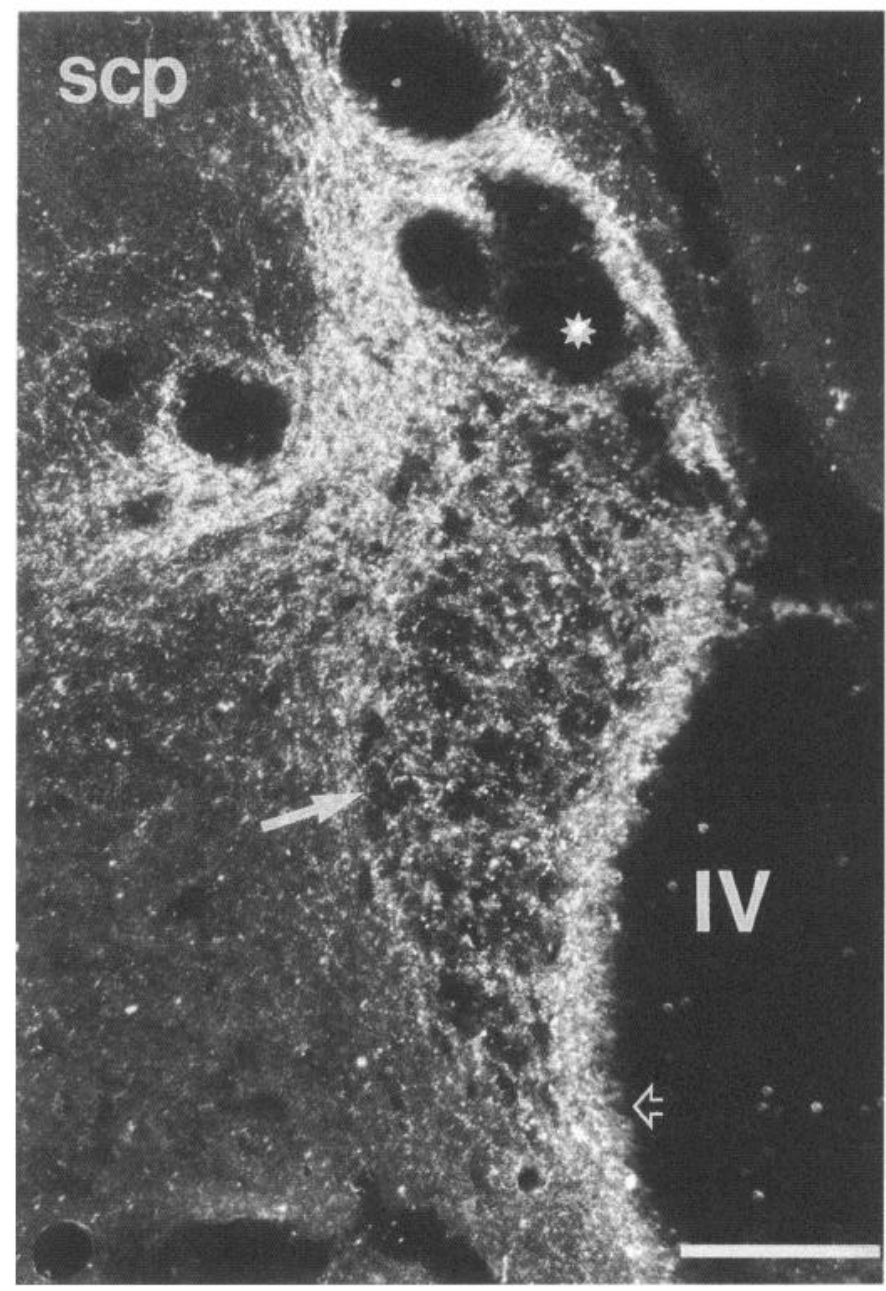

Figure 1. Dark-field photomicrograph of a coronal section $(16 \mu \mathrm{m}$ thick) depicting ENK-ir innervation of the $\mathrm{LC}$ region (ABC-peroxidase reaction). Note the moderately dense plexus of punctate ENK-ir fibers and terminals within LC (at solid arrow). Notice also the ENK immunoreactivity medial and ventromedial to LC (at open arrow), in the area of LC dendrites. Also note that lateral and dorsal to LC the nucleus parabrachialis receives a dense ENK-ir innervation (surrounding blood vessel at asterisk). Orientation: dorsal is at top and medial is at right. $I V$, fourth ventricle; $s c p$, superior cerebellar peduncle. Scale bar, 160 $\mu \mathrm{m}$.

caudally between the inferior olive and nucleus gigantocellularis medially, and the spinal trigeminal nucleus and nerve laterally (Paxinos and Watson, 1986). The PrH region in the rostral dorsomedial medulla extends approximately $2 \mathrm{~mm}$ rostrocaudally, from the XIIth nerve nucleus in the rostral medulla to the genu of the VIIth nerve in the pons. Rostral PrH levels correspond to the levels represented in atlas plates 61-63, and the caudal aspect of PrH corresponds to the levels shown in plates 64-66 (Paxinos and Watson, 1986). Locations and nomenclature of anatomical structures were taken from this same atlas.

\section{Results}

Distribution of ENK-ir fibers in the LC and peri- $L C$ In colchicine-treated $(n=8)$ or untreated animals $(n=5)$, ENKir fibers were prominent throughout the pons and the medulla. A moderately dense plexus of ENK-ir fibers was observed throughout the nucleus LC. Many of the ENK-ir fibers and varicosities in the LC appeared to surround LC perikarya. In coronal sections, the ENK immunoreactivity within the LC was mainly punctate with occasional short segments of ENK-ir fibers (Fig. 1). In contrast, in horizontal sections, ENK-ir fiber segments were substantially greater in number and length, and were primarily oriented along the rostrocaudal dimension of the LC nucleus (Fig. 2). It was also more obvious in horizontal than in coronal sections that the LC was more densely innervated by ENK-ir fibers in the rostral part of the nucleus (Figs. 2, 3).

There were also prominent ENK-ir terminals in certain regions surrounding the LC nucleus proper. In coronal sections, ENKir fibers were very dense in the thin zone between the nucleus $\mathrm{LC}$ and the IVth ventricle, and also in the parabrachial nucleus dorsolateral to the LC (Fig. 1). In horizontal sections, dense ENK-ir fibers were readily identified in a narrow region adjacent to the ependyma of the IVth ventricle along the length of the nucleus LC rostromedially and caudally (Figs. 2, 3). It is noteworthy that the distribution of dense ENK-ir in some pericoerulear regions overlapped with the distribution of extranuclear TH-ir processes of LC neurons (Fig. 2). This was particularly obvious in the region rostromedial to the LC and along the IVth ventricle medially adjacent to the LC where extranuclear dendrites of LC neurons are extensive (Fig. 3; Fu et al., 1989). The density of ENK-ir fibers in pericoerulear regions was often greater than that within the LC proper.

In some animals, alternate sections were also immunostained with an antibody directed against met-enkephalin. There were no apparent differences in the pattern or distribution of ENKir fibers in the LC and peri-LC regions seen with this antibody compared to that described above for the antibody to the extended ENK molecule.

\section{ENK-ir somata in the $L C$ region}

No ENK-ir neurons were observed in the LC nucleus proper in either colchicine-treated or untreated rats (Figs. 1-3). However, ENK-ir cell bodies were visualized in regions surrounding the LC nucleus in colchicine animals. In particular, the parabrachial and the sphenoid nuclei exhibited dense clusters of ENK-ir cell bodies. Numerous small and round $(<15 \mu \mathrm{m})$ ENK-ir cell bodies were located in the ventral and dorsal aspects of the rostral part of the parabrachial nucleus (15-90 cells per section). There were also numerous ENK-ir cell bodies of medium size (15-25 $\mu \mathrm{m})$ located in the sphenoid nucleus just dorsal to the dorsal tegmental nucleus of Gudden (DTg; $>25$ cells per section). Scattered ENK-ir neurons ( $<10$ per section) were also visualized in Barrington's nucleus, the pontine central gray, and within the mesencephalic nucleus of the trigeminal nerve.

\footnotetext{
Figure 2. Montages of fluorescent photomicrographs of a horizontal section (16 $\mu \mathrm{m}$ thick) showing the overlap of ENK-ir fibers with TH-ir cell bodies and processes within and surrounding LC. $A$, distribution of TH-ir cell bodies demarcating the nucleus LC, and TH-ir processes in the periLC area (FITC labeled). B, ENK immunoreactivity in the same section (RITC labeled). Note the moderately dense plexus of ENK-ir fibers and terminals within the nucleus LC proper as well as the dense ENK immunoreactivity immediately medial and lateral to LC, in the area of extranuclear LC dendrites. Note also that, compared to Figure 1, there are long lengths of ENK-ir fibers, indicating that the ENK innervation of LC may be oriented rostrocaudally. Orientation; rostral is at right and medial is at bottom. IV, fourth ventricle. Asterisks and stars denote corresponding blood vessels. Scale bar, $25 \mu \mathrm{m}$.
} 

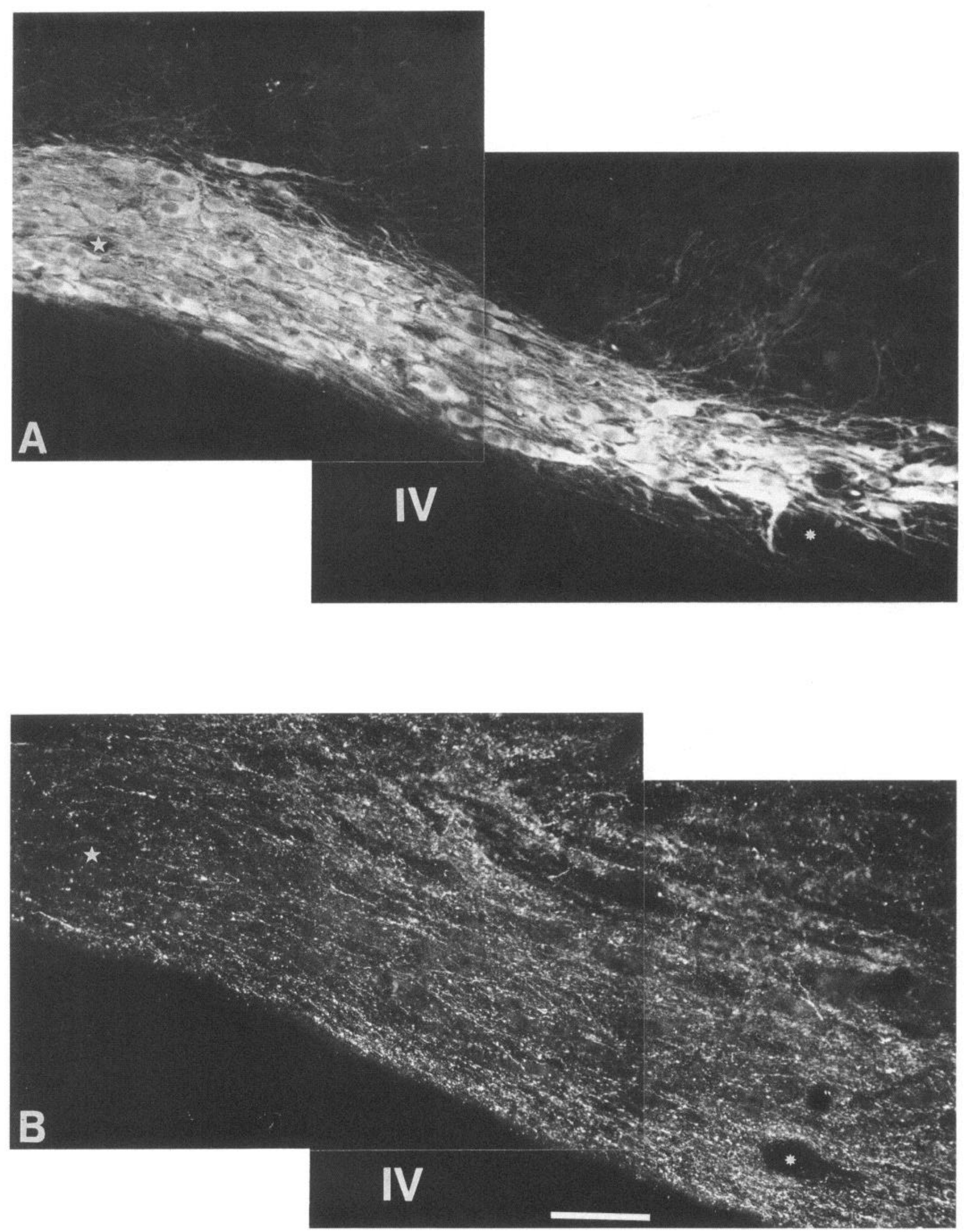

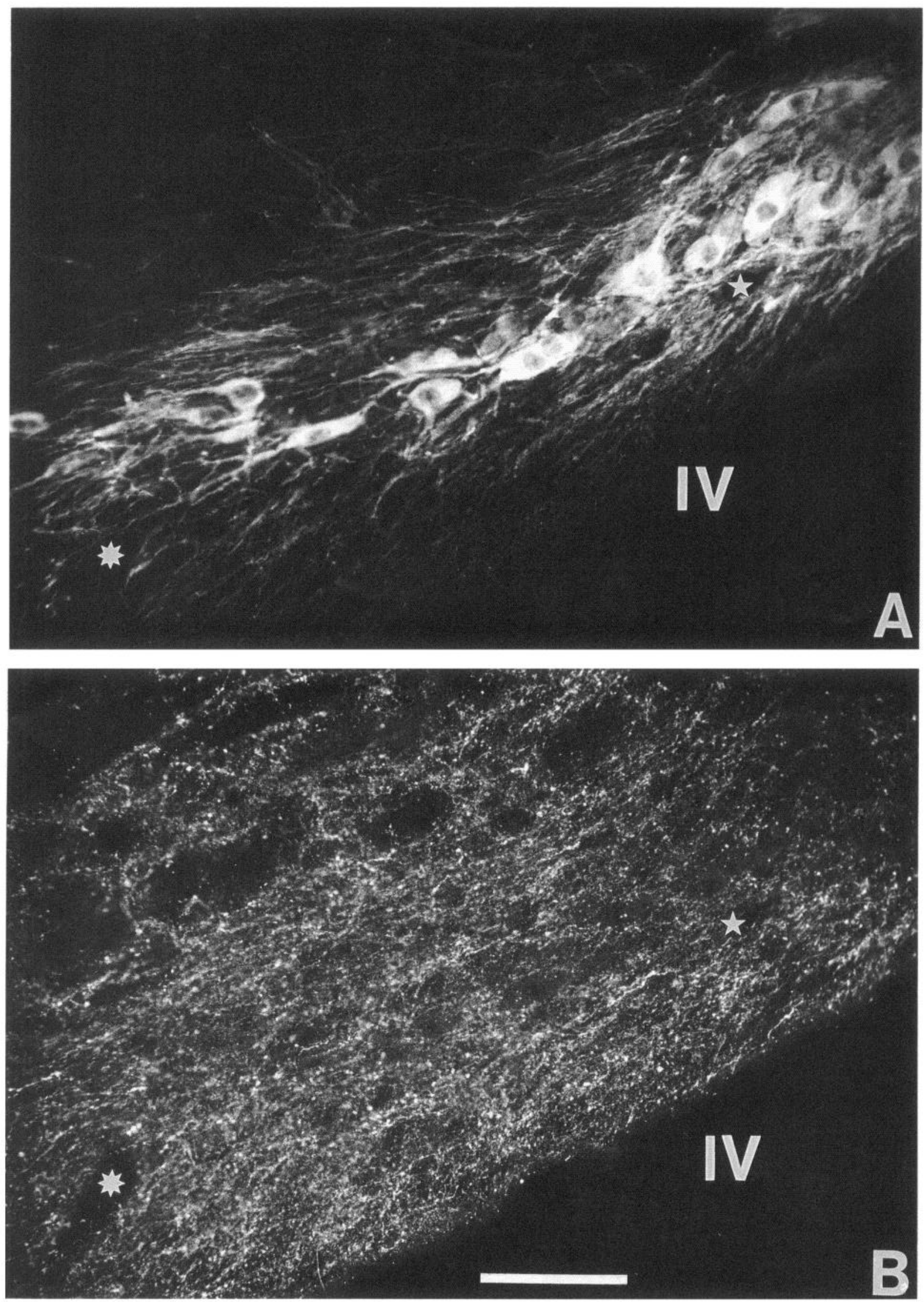

Figure 3. Fluorescent photomicrographs of a horizontal section (16 $\mu \mathrm{m}$ thick), showing the rostral portion of LC. $A$, TH immunoreactivity, revealing noradrenergic LC cell bodies and processes (FITC labeling). $B$, ENK immunoreactivity in the same section (RITC labeling). Note that the LC and surrounding area of LC processes are densely innervated by ENK-ir fibers in the rostral part of the nucleus. Orientation: rostral is at left and medial is at bottom. IV, fourth ventricle. Asterisks and stars denote blood vessels. Scale bar, $20 \mu \mathrm{m}$. 


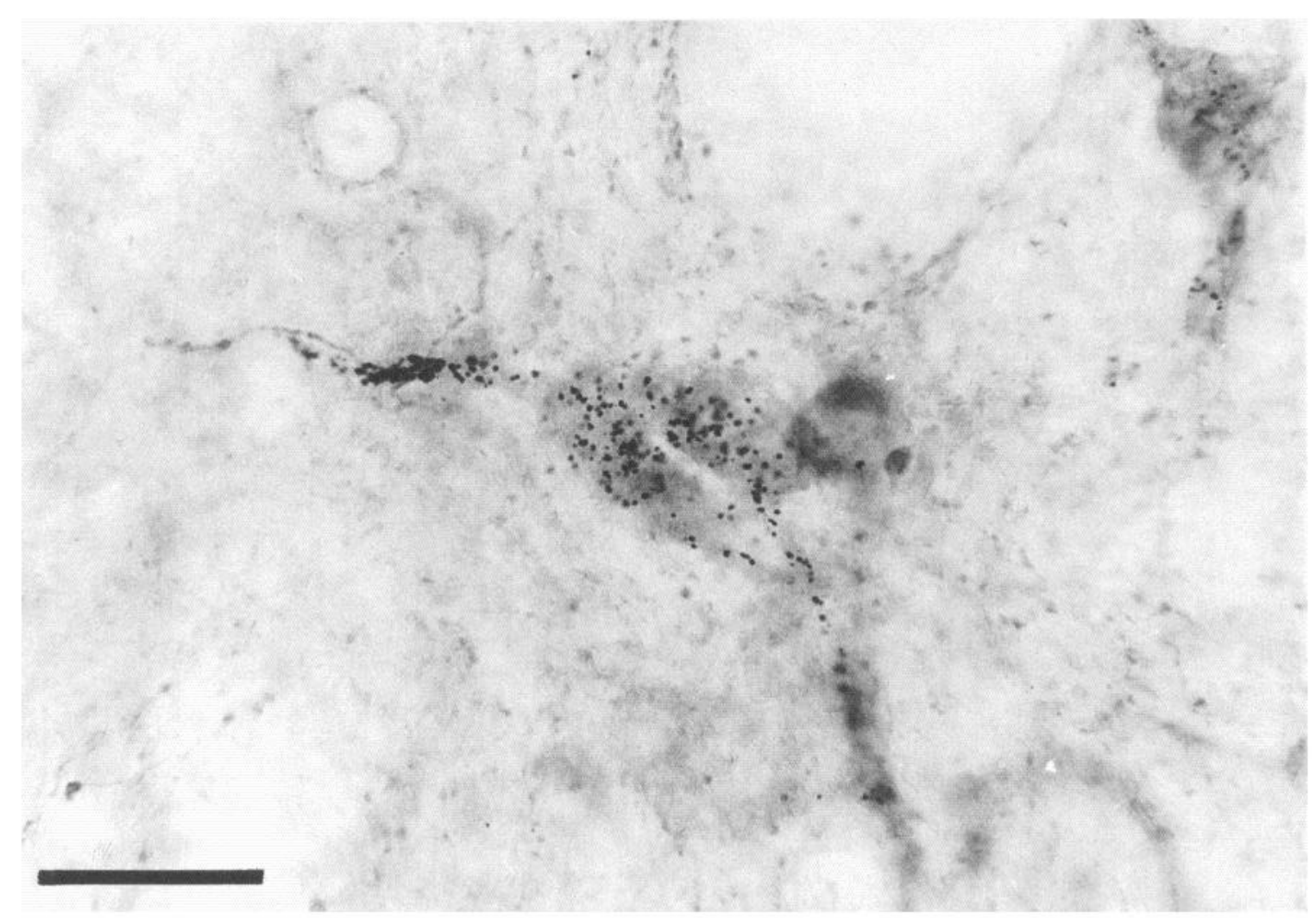

Figure 4. High-power bright-field photomicrograph of a coronal $40-\mu \mathrm{m}$-thick section depicting retrogradely labeled ENK-ir neurons in retrofacial (mid) PGi, from a rat with a WGA-apoHRP-Au injection in the ipsilateral LC. The silver-intensified WGA-apoHRP-Au retrograde label forms black granules as seen under bright-field illumination. The ENK immunoreactivity appears as a diffuse brown reaction product. Scale bar, $40 \mu \mathrm{m}$.

\section{Distribution of ENK-ir neurons in the PGi and PrH}

In colchicine-treated animals, ENK-ir neurons were found dispersed throughout the rostrocaudal length of the PGi, extending from the anterior pole of the lateral reticular nucleus to the caudal third of the facial nucleus. The neurons were distributed in a conical caudorostral column, which appeared largest in the caudal PGi and narrow in the rostral, juxtafacial PGi (Van Bockstaele et al., 1989). ENK-ir neurons were present between the inferior olive caudomedially and the spinal trigeminal nucleus caudolaterally, and between the pyramidal tract and nucleus gigantocellularis (pars alpha) rostromedially and the facial nucleus rostrolaterally (Figs. 4, 5). A small group of ENK-ir neurons was also found in a cluster dorsal to the dorsal accessory olive. Overall, ENK-ir neurons were more numerous in the caudal and mid-PGi than in the rostral juxtafacial part of the nucleus (Table 1, Fig. 5). The ENK-ir neurons in the PGi were small ( $<15 \mu \mathrm{m}$ diameter), medium $(15-25 \mu \mathrm{m})$, or large ( $>25$ $\mu \mathrm{m})$ and of various shapes including multipolar, ellipsoidal, round, or triangular. The supraolivary group of ENK-ir cells were oval and medium in size (15-25 $\mu \mathrm{m}$ diameter).

In the rostral dorsomedial medulla (region of the PrH), ENKir neurons were largely restricted to the medial perifasicular aspect of the nucleus PrH and the subjacent medial longitudinal fasciculus (mlf). ENK-ir neurons were compactly located within the medial PrH along its length, from the anterior aspect of the hypoglossal nucleus to the genu of the VIIth nerve (Fig. 6). ENKir neurons also extended ventrally along the lateral borders of the mlf(Fig. 5). The ENK-ir neurons within medial PrH proper were typically small and round or ellipsoidal $(<15 \mu \mathrm{m})$, while those located along the mlf borders were larger $(15-25 \mu \mathrm{m})$ and more dispersed.

\begin{tabular}{|c|c|c|c|c|}
\hline & $\begin{array}{l}\text { ENK-ir } \\
\text { neurons }\end{array}$ & $\begin{array}{l}\text { WGA- } \\
\text { apoHRP- } \\
\text { Au } \\
\text { neurons }\end{array}$ & $\begin{array}{l}\text { WGA- } \\
\text { apoHRP- } \\
\text { Au }+ \\
\text { ENK-ir }\end{array}$ & $\begin{array}{l}\% \text { Double } \\
\text { labeled }^{a}\end{array}$ \\
\hline \multicolumn{5}{|l|}{ PGi } \\
\hline Caudal & 146 & 45 & 29 & $64 \%$ \\
\hline Retrofacial & 119 & 56 & 33 & $59 \%$ \\
\hline Juxtafacial & 55 & 20 & 7 & $34 \%$ \\
\hline All levels & 320 & 121 & 69 & $57 \%$ \\
\hline \multicolumn{5}{|l|}{ PrH } \\
\hline Caudal & 64 & 36 & 19 & $53 \%$ \\
\hline Caudal & 64 & 39 & 23 & $59 \%$ \\
\hline Both levels & 128 & 75 & 42 & $56 \%$ \\
\hline
\end{tabular}

Each level of PGi or PrH extended 120-160 $\mu \mathrm{m}$ (three or four sections) throughout the rostrocaudal limits of each nucleus. This compilation is the average absolute number of cells counted in the sections analyzed from three (PGi) or four $(\mathrm{PrH})$ rats; the estimated total numbers of cells would be approximately four times the values shown here. It is noteworthy that the proportion of doubly labeled neurons did not appear to vary substantially with different sizes of WGA-apoHRP-Au injections in LC, while the number of retrogradely labeled cells was greater for larger deposits of WGA-apoHRP-Au in LC.

${ }^{a}$ Refers to WGA-apoHRP-Au + ENK-ir neurons $\div$ total number of WGAapoHRP-Au neurons. 
- ENK-ir

$\triangle$ WGA-apoHRP-Au

ENK-ir + WGA-apoHRP-Au caudal PrH

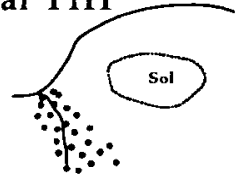

$\therefore$

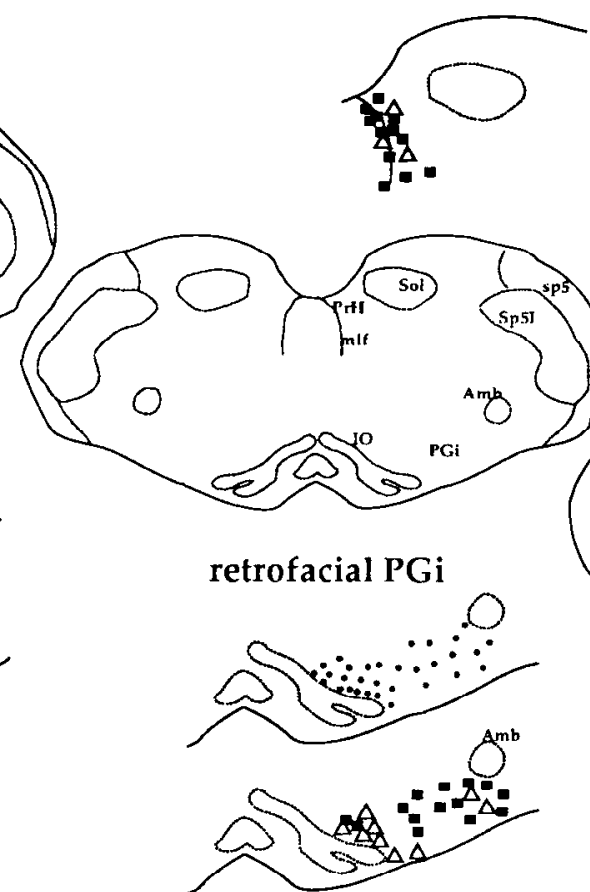

rostral PrH
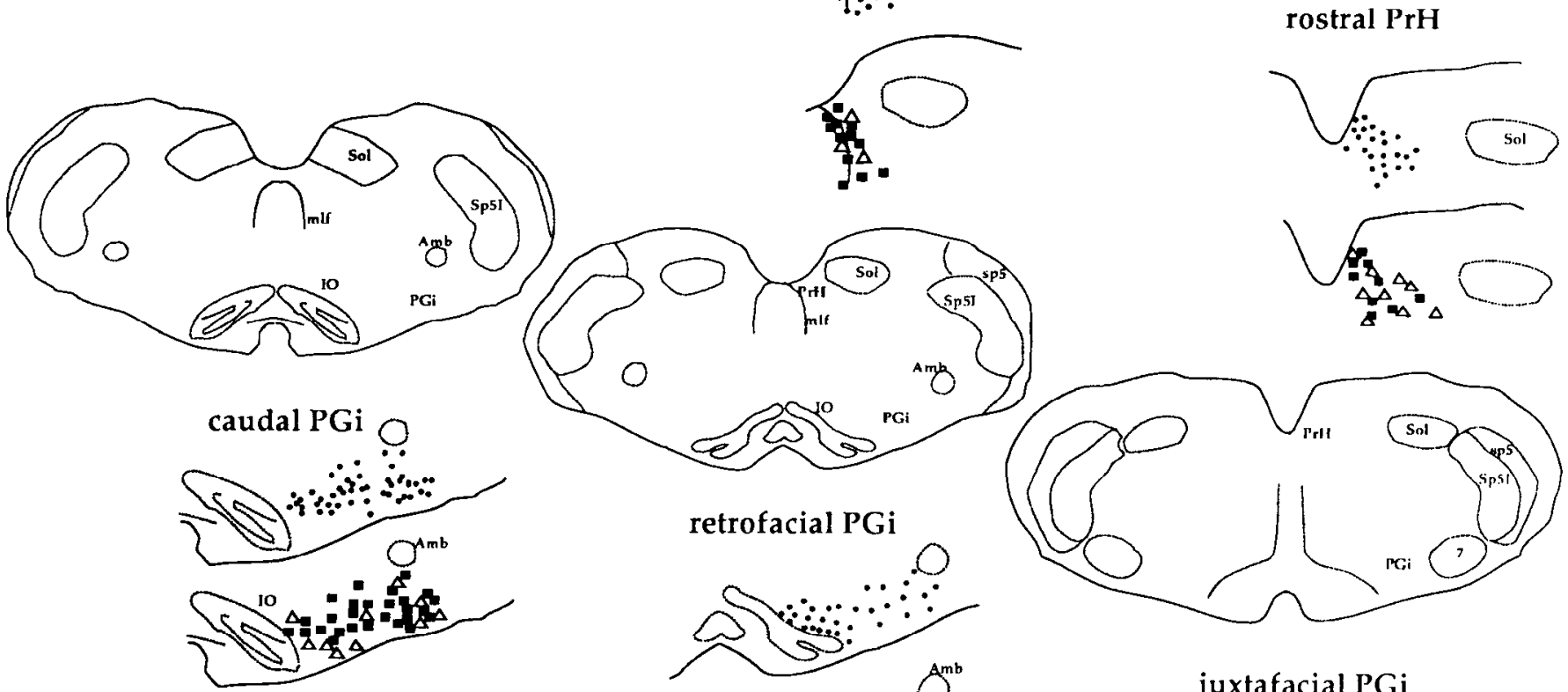

juxtafacial PGi

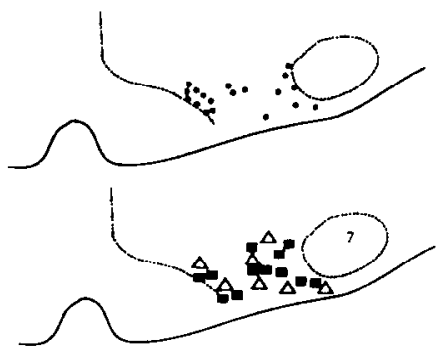

Figure 5. Camera lucida drawings of coronal sections through the rostral medulla illustrating the distribution of neurons immunoreactive for enkephalin (ENK-ir; solid circles), retrogradely labeled with WGA-apoHRP-Au (open triangles), or doubly labeled (WGA-apoHRP-Au + ENK-ir; solid squares). These sections correspond to the three different levels of PGi and two levels of PrH, as indicated, and are arranged, left to right, from caudal to rostral. Full sections without cells plotted indicate the levels of the corresponding hemisection plots above $(P r H)$ and below $(P G i)$. Cells at each level are plotted in two identical hemisections of the PGi and PrH to indicate ENK-ir neurons (upper) and retrogradely labeled and doubly labeled neurons (lower). These data are from a typical rat with a WGA-apoHRP-Au injection in the ipsilateral LC; plots in hemisections are of all labeled neurons in the PGi or $\mathrm{PrH}$ area in individual sections ( $40 \mu \mathrm{m}$ thick). $A m b$, nucleus ambiguus; $I O$, inferior olive; $S o l$, nucleus of the solitary tract; $\mathrm{PrH}$, prepositus hypoglossi nucleus; $s p 5$, spinal tract of trigeminal nerve; $S p 5 I$, nucleus of the spinal tract of the trigeminal nerve pars interpolaris; $m l f$, medial longitudinal fasiculus; $P G i$, nucleus paragigantocellularis; 7 , facial nucleus.

\section{Distribution of LC afferents, ENK-ir perikarya, and doubly labeled neurons in the rostral medulla}

Injections of 150-300 $\mathrm{nl}$ of WGA-apoHRP-Au centered in the LC $(n=6)$ yielded injection sites that were primarily restricted to the nucleus LC proper (Fig. 7). Such injections yielded many retrogradely labeled neurons in the PGi and PrH. Retrogradely labeled neurons followed the same pattern described in previous studies using WGA-HRP (Aston-Jones et al., 1986, 1990) or fluoro-gold (Astier et al., 1987; Pieribone et al., 1988; Pieribone and Aston-Jones, 1991).

$P G i$. In the PGi, the cells retrogradely labeled with WGAapoHRP-Au were distributed throughout the three subregions of the PGi described above (Fig. 5; Van Bockstaele et al., 1989; Van Bockstaele and Aston-Jones, in press). The retrogradely labeled neurons were distributed between the inferior olive cau- domedially, the spinal trigeminal nucleus caudolaterally, the pyramidal tract and the nucleus gigantocellularis pars alpha rostromedially, and the facial nucleus rostrolaterally. Retrograde labeling was mainly ipsilateral, but labeled neurons were also identified in the contralateral PGi.

Examination of ENK-ir and retrograde labeling in the same tissue sections revealed an unexpectedly high incidence of doubly labeled neurons in the PGi (Fig. 5). Overall, $57 \%$ of retrogradely labeled, LC-afferent neurons were immunoreactive for ENK. The percentage of LC afferents that were doubly labeled in the rostral portion of PGi (juxtafacial PGi) was $34 \%$, as compared to $59 \%$ in the mid (retrofacial) PGi and $64 \%$ in the caudal portion of PGi (Table 1).

The ENK-ir neurons in the PGi that projected to the LC were variable in morphology. They were medium $(15 \times 25 \mu \mathrm{m})$ or large $(20 \times 25-35 \mu \mathrm{m})$ ellipsoidal or triangular multipolar neu- 


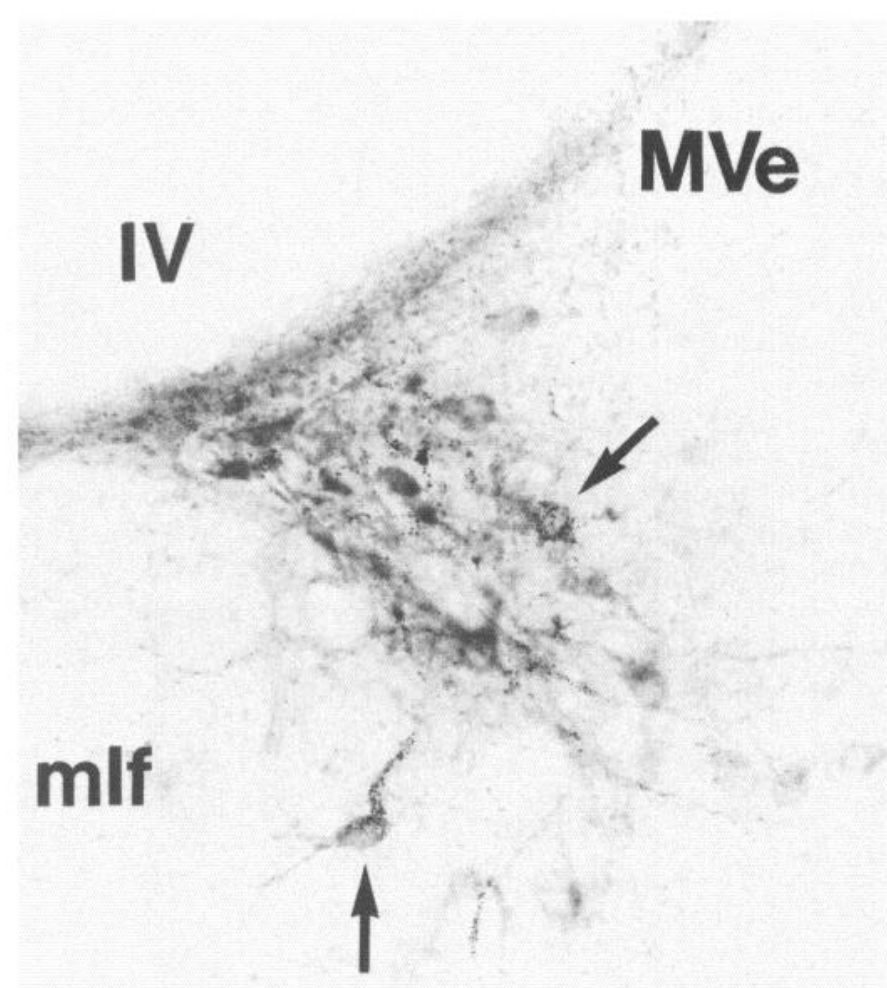

Figure 6. Low-power bright-field photomicrograph of a coronal 40$\mu$ m-thick section depicting retrogradely labeled ENK-ir neurons in the PrH from a rat with a WGA-apoHRP-Au injection in LC. The silverintensified WGA-apoHRP-Au retrograde label appears as black granules, and the ENK immunoreactivity appears as a diffuse brown reaction product. Sample doubly labeled cells are indicated by arrows. Note that ENK-ir neurons are located in the medial aspect of the PrH, immediately dorsal to the mlf. Dorsal is at the top, and midline is to the left. IV fourth ventricle; $M V e$, medial vestibular nucleus; $m l f$, medial longitudinal fasiculus. Scale bar, $100 \mu \mathrm{m}$.

rons, while small $(<15 \mu \mathrm{m})$ round neurons with both labels were observed less frequently.

$\mathrm{PrH}$. In the dorsomedial medulla, LC afferents were densely aggregated in the medial $\mathrm{PrH}$ along the dorsolateral border of the mlf where it abuts the fourth ventricle as well as more ventrally along the subjacent lateral borders of the mlf (Figs. 5 , 6). Retrogradely labeled neurons were largely restricted to this medial perifasicular aspect of the nucleus $\mathrm{PrH}$ and the subjacent mlf, and were located along the entire length of the PrH. Retrograde labeling was bilateral with a slight contralateral predominance.

As found for the PGi, examination of ENK-ir and retrogradely labeled neurons in the same tissue sections revealed a surprisingly high incidence of double labeling. Overall, $56 \%$ of colloidal gold-labeled, LC-projecting neurons in $\mathrm{PrH}$ were also immunoreactive for ENK (Table 1). There was no apparent difference in the numbers or distributions of ENK-ir cells projecting to $\mathrm{LC}$ in the rostral versus caudal aspects of the PrH.

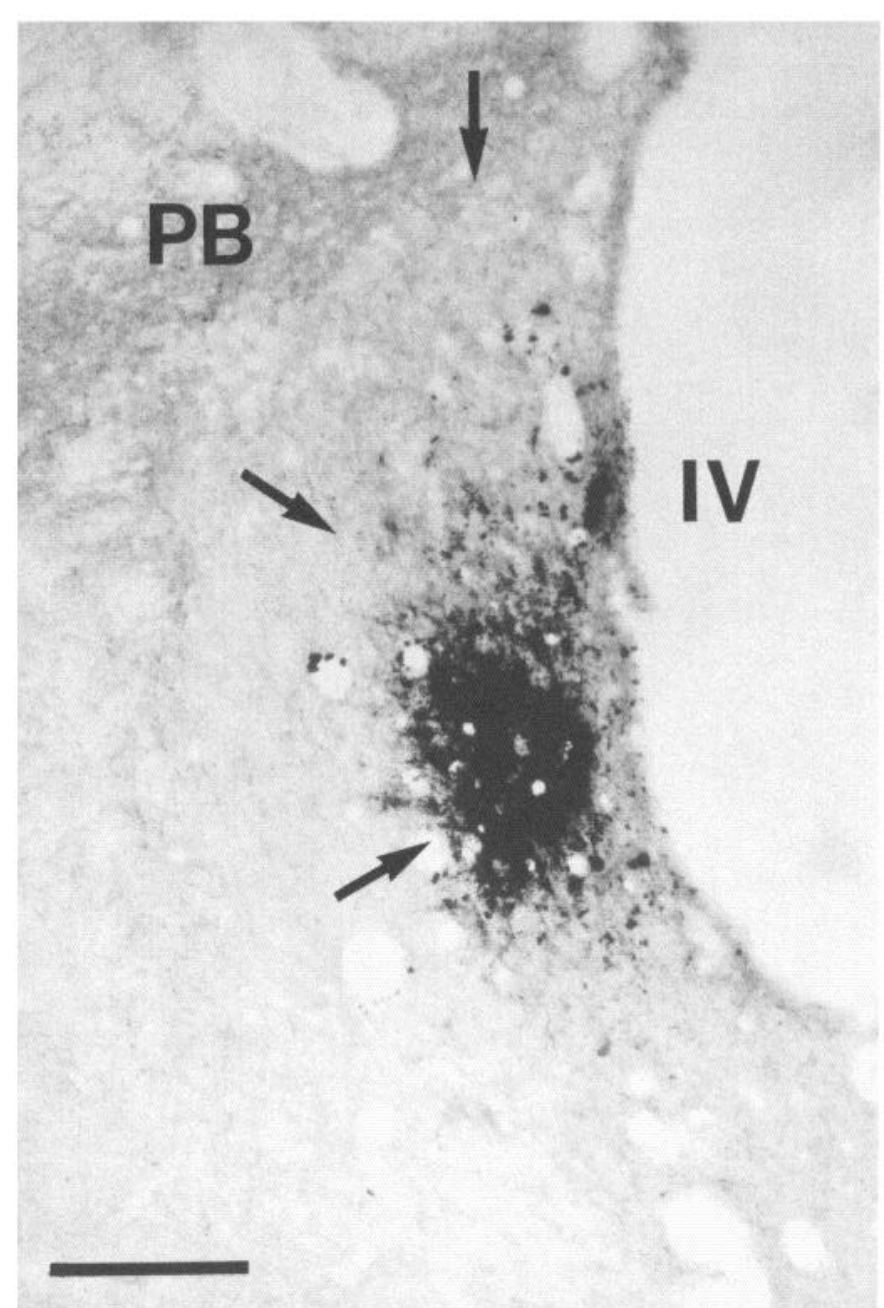

Figure 7. Bright-field photomicrograph of a coronal section depicting an injection $(150 \mathrm{nl})$ of WGA-apoHRP-Au in the LC. Dense, focal WGA-apoHRP-Au deposits were made by pressure injection into the LC through glass micropipettes, as described in Materials and Methods. In this particular example, the injection of WGA-apoHRP-Au was restricted to the ventral two-thirds of LC (lateral and dorsal boundaries of the LC nucleus are indicated by arrows); this field represents the maximum size of this injection, and is typical of injections in this study. Such restricted injections sites produced robust retrograde labeling in both the PGi and the PrH. Orientation: dorsal is at top and medial is at right. $I V$, fourth ventricle; $P B$, parabrachial nucleus. Scale bar, 200 $\mu \mathrm{m}$.

The ENK-ir neurons in the $\mathrm{PrH}$ that projected to the $\mathrm{LC}$ were variable in morphology, being round (10-15 $\mu \mathrm{m}$ diameter), ellipsoidal $(15 \times 25 \mu \mathrm{m})$, or fusiform cells $(10 \times 15-30 \mu \mathrm{m})$.

\section{Comparison between LC afferents}

There were no apparent differences in the intensities of staining of ENK-ir neurons that were singly or doubly labeled in PGi or $\mathrm{PrH}$. Moreover, it is noteworthy that while the number of retrogradely labeled neurons was greater for larger deposits of WGAapoHRP-Au in LC, the proportion of doubly labeled neurons did not appear to vary substantially with different sizes of WGAapoHRP-Au injections in LC. For example, in the PGi, with an injection of WGA-apoHRP-Au that covered most of the LC, we observed that 114 of 188 retrogradely labeled cells were also immunoreactive to ENK (61\%), compared to 29 of 49 with an 
injection that was restricted to one-third of $\mathrm{LC}$. In $\operatorname{PrH}$, we observed that 86 of 148 retrogradely labeled cells were also immunoreactive to ENK (58\%) compared to 16 of 25 with an injection that was restricted to one-third of $\mathrm{LC}$.

\section{Control procedures}

In some rats $(n=3)$, WGA-apoHRP-Au deposits were centered outside of the LC in the peri-LC area and included structures such as the lateral dorsal tegmental nucleus, Barrington's nucleus, or the region lateroventral to LC. In all cases LC neurons were labeled, but it was unclear whether this resulted from diffusion from the injection site or capture by extranuclear LC dendrites. For injections located outside of the LC, the number of retrogradely cells in the $\mathrm{PGi}$ and $\mathrm{PrH}$ was greatly reduced, even with large injection sites. In these cases, retrogradely labeling was observed in areas (e.g., the nucleus tractus solitarii, vestibular nucleus) that project to structures surrounding LC but not to the LC proper (Aston-Jones et al., 1986, 1991). On average, such injections yielded two or three retrogradely labeled cells per $40-\mu \mathrm{m}$-thick section in the PGi compared to an average of 18 or 19 LC-projecting PGi cells when the injection was centered in the LC. Likewise, in the PrH the number of retrogradely labeled neurons was greatly diminished following injections outside the LC, which yielded an average of one retrogradely labeled cell per section in the $\mathrm{PrH}$ compared to 12 or $13 \mathrm{LC}$-projecting cells in $\mathrm{PrH}$ for cases with injections centered in the LC. In these cases with pericoerulear injections, the number of doubly labeled cells was similarly reduced, and the percentage of double labeling appeared to vary with the amount of tracer that diffused into the $\mathrm{LC}$.

Although the ENK antibody was previously characterized (Weber et al., 1982; Fallon and Leslie, 1986; Ménétrey and Basbaum, 1987), control procedures here confirmed its specificity. Experiments $(n=2)$ in which the primary antisera was replaced with bovine serum albumin yielded no immunoreactivity in tissue sections. Experiments $(n=2)$ in which the primary antiserum was first preabsorbed for 12 or $20 \mathrm{hr}$ with 133 $\mu \mathrm{M}$ of Met-enkephalin-Arg ${ }^{6}-\mathrm{Gly}^{7}-\mathrm{Leu}^{8}$ also produced no immunoreactivity in tissue sections.

\section{Discussion}

The present findings suggest that more than half of the LCprojecting neurons in the major LC-afferent nuclei in both the rostroventral medulla (nucleus $\mathrm{PGi}$ ) and dorsomedial medulla (medial nucleus PrH) were also immunoreactive for ENK, and therefore that ENK neurons in the rostral medulla are prominent among the afferents to LC neurons. Given that the Met-enkephalin-Arg ${ }^{6}-\mathrm{Gly}^{7}-\mathrm{Leu}^{8}$ is derived exclusively from proenkephalin A, antibodies directed against this precursor product represent a good marker for the distribution of neurons expressing enkephalin. The extended enkephalin could represent a biosynthetic intermediate precursor to met-enkephalin (Kilpatrick et al., 1981; Comb et al., 1982; Lewis and Stern, 1983) or could itself be an endogenous ligand for opioid receptors (Kilpatrick et al., 1981; Herz, 1984).

ENK-ir fibers in the LC have been previously reported (Simantov et al., 1977; Sar et al., 1978; Pickel et al., 1979; Uhl et al., 1979; Finley et al., 1981 a; Watson et al., 1982; Khachaturian et al., 1983; Williams and Dockray, 1983; Petrusz et al., 1985; Fallon and Leslie, 1986; Murakami et al., 1987). However, the present study revealed a more prominent ENK innervation of
LC than had been previously described, perhaps due to (1) the use of thin (14- $\mu \mathrm{m}$-thick) sections and (2) the use of horizontal sections, as ENK-ir fibers appear to be preferentially oriented rostrocaudally within the $\mathrm{LC}$. We also describe a previously unreported dense ENK-ir terminal field in pericoerulear zones, particularly in the rostromedial and the caudal juxtaependymal regions adjacent to the $L C$ nucleus. The processes of LC neurons have been reported to extend outside the $\mathrm{LC}$ cell body region for hundreds of microns (Swanson, 1976; Grzanna and Molliver, 1980). More recently, Shipley and colleagues (Fu et al., 1989; Shipley et al., 1990; M. T. Shipley, L. Fu, M. Ennis, and G. Aston-Jones, unpublished observations) have reported that nearly all the noradrenergic processes in the rostromedial and caudal juxtaependymal pericoerulear zones were dendrites of LC neurons. Moreover, most or perhaps all individual LC neurons have extranuclear dendrites that extend into one or both of these pericoerulear zoncs (Shiplcy ct al., 1990). These results suggest that, in addition to influencing LC perikarya, ENK fibers may also innervate LC dendrites outside of the immediate IC. cell body region and influence a large postsynaptic surface of LC neurons. Pickel et al. (1979) have shown numerous axodendritic contacts by ENK-ir terminals within the LC nucleus, supporting a neurotransmitter role for endogenous enkephalin in LC. Similar electron microscopic analysis is necessary to determine whether ENK-ir fibers in the extranuclear dendritic zones identified here innervate LC dendrites. It is also possible that these ENK-ir pericoerulear fibers innervate the dendrites or somata of non-LC neurons located in this region around LC. Our recent studies (Aston-Jones et al., 1991) indicate that pericoerulear neurons may also innervate the LC, so this is another possible avenue for ENK influence over $\mathrm{LC}$ discharge. Further studies are needed to test these possibilities.

Proenkephalin-immunoreactive neurons and fibers have been described in the LC region of different species including rat (Sar et al., 1978; Pickel et al., 1979; Uhl et al., 1979; Finley et al., 1981 a; Watson et al., 1982; Khachaturian et al., 1983; Williams and Dockray, 1983; Petrusz et al., 1985; Fallon and Leslie, 1986; Murakami et al., 1987), cat (Charnay et al., 1982; Reddy et al., 1990), monkey (Ibuki et al., 1989), and opossum (Cassini et al., 1989). Although the degree of innervation appears to be similar among these species, the presence of ENK-ir cell bodies in LC varied among the different animals. In the cat (Charnay et al., 1982; Reddy et al., 1990) and the opossum (Cassini et al., 1989), a substantial number of LC neurons were also found to be immunoreactive for ENK. However, in the rat there is a disagreement in the literature regarding the presence of ENK-ir neurons in the LC. Some early studies reported the existence of leuenkephalin-like-immunoreactive perikarya in the noradrenergic LC (Finley et al., 1981 b) and also with antisera against either the heptapeptide Met-enkephalin-Arg ${ }^{6}-\mathrm{Gly}^{7}$ or bovine adrenal medulla peptide (BAM 22P) (Khachaturian et al., 1983). More recent studies in rat (Sar et al., 1978; Pickel et al., 1979; Uhl et al., 1979; Finley et al., 1981 a; Watson et al., 1982; Khachaturian et al., 1983; Williams and Dockray, 1983; Petrusz et al., 1985; Fallon and Leslie, 1986; Murakami et al., 1987) and monkey (Ibuki et al., 1989) report no, or only occasional, ENK-ir cells in the LC or subcoeruleus region. We observed no ENK-ir neurons in the nucleus LC proper although occasional ENK-ir ncurons could be seen in the peri-LC region. However, in agreement with previous studies (Sar et al., 1978; Pickel et al., 1979; Uhl et al., 1979; Finley et al., 1981a; Watson et al., 1982; Khachaturian et al., 1983; Williams and Dockray, 1983; Petrusz et al., 
1985; Fallon and Leslie, 1986; Murakami ct al., 1987), we found that ENK-ir cell bodies were clustered in the ventral and dorsal aspects of the parabrachial nucleus and the sphenoid nucleus (dorsal to the DTg), and were also scattered in Barrington's nucleus, in the mesencephalic nucleus of the trigeminal nerve, and in the pontine central gray. The discrepancy concerning ENK-ir neurons in LC of cat versus rat or monkey may reflect the neurochemical differences among the LCs of these species. In particular, whereas rat and monkey LC is composed nearly entirely of NE-containing neurons (Foote et al., 1983), cat LC is heavily interdigitated with non-NE neurons, and the ENK-ir cells reported in the $\mathrm{LC}$ of this species may correspond to some of these non-NE cells. Other discrepancies among reports may be related to the use of different antibodies. In a recent study, Murakami et al. (1989) reported no ENK-ir neurons among the TH-ir cells of the LC whereas colocalization of ENK and TH immunorcactivity was obscrved in some neurons of the medullary adrenergic cell groups.

In the present study, we confirmed previous results that the LC is strongly innervated from the rostral medulla by two nuclei, the PGi and the PrH (Aston-Jones et al., 1986, 1990, 1991; Pieribone and Aston-Jones, 1991). The most surprising finding was the large proportion, approximately $60 \%$, of LC afferent neurons in both the PGi and the PrH that were immunoreactive for ENK, indicating that ENK neurons in the rostral medulla represent a prominent class of afferents to the LC. It is possible that some of this robust retrograde labeling resulted from uptake of the tracer by nonterminal fibers passing through the LC. However, previous studies have found that direct injections of WGA-apoHRP-Au into peripheral or central nerve tracts produced little or no retrograde labeling (Ménétrey, 1985; Mênétrey and Basbaum, 1987). To also examine this possibility, we injected WGA-apoHRP-Au into the pyramidal tract in the rostral medulla of one rat, and observed no labeled neurons in the cortex or elsewhere (E. J. Van Bockstaele and G. Aston-Jones, unpublished observations). These results suggest that this tracer is not taken up and transported to a large degree by passing fibers. It is also possible that the passage of the pipette through the region dorsal to the $\mathrm{LC}$ led to reflux of the tracer into the pipette track, which may contribute to the neuronal labeling. However, with the long periods used here for ejection, the tracer was not observed along the pipette tract. In addition, injection sites centered outside of the LC but approaching the LC region in the same dorsal fashion did not yield extensive or consistent retrograde labeling in the PrH or the PGi. In fact, the extent of retrograde labeling in the $\mathrm{PGi}$ and $\mathrm{PrH}$ appeared to be proportional to the extent that the tracer filled or diffused into the LC rather than to the size of the injection site. Moreover, it is noteworthy that while the number of retrogradely labeled neurons was greater for larger deposits of tracer in the LC (presumably corresponding to more complete filling of $\mathrm{LC}$ ), the proportion of doubly labeled neurons did not appear to vary substantially with different sizes of tracer injections in the nucleus LC. These considerations make it seem unlikely that the present results were a consequence of abberrant uptake by fibers not terminating in LC. This conclusion is further supported by previous findings (discussed above) that (1) the LC is well innervated by ENK-ir fibers, (2) numerous ENK-ir somata are found in the PGi and PrH, and (3) major inputs to the LC arise from these two medullary nuclei. Nonetheless, possible extraneous sources of retrograde labeling cannot be ruled out in a light microscopic study, and electron microscopic examination is needed to discern fully the synaptic characteristics of medullary ENK innervation of the LC area.

Neurons in the PGi have also been found to provide a putative adrenergic input to LC. A previous study found that the PGi provided the major adrenergic innervation of $\mathrm{LC}$, with $21 \%$ of LC afferent neurons in PGi staining for phenylethanolamine$N$-methyltransferase (PNMT), a marker of adrenergic neurons (Pieribone and Aston-Jones, 1991). Coexistence between ENK and PNMT has been reported in the ventrolateral medulla (Ceccatelli et al., 1989). However, the rostrocaudal distribution of retrogradely labeled cells in PGi that stained for PNMT was different from that found here for ENK. There is a high percentage $(80 \%)$ of LC afferents in the rostral portion of PGi that also stained for PNMT, while in the mid and caudal portions of PGi only $18 \%$ of the retrogradely labeled cells were PNMT positive (Pieribone and Aston-Jones, 1991). In contrast, we found that a higher proportion of LC-projecting neurons were immunoreactive for ENK in the caudal and mid-PGi compared to its rostral division. Interestingly, Murakami et al. (1989) reported that the percentage of colocalization of ENK immunoreactivity in catecholamine neurons in the $\mathrm{Al} / \mathrm{Cl}$ region (which included PGi) was higher in the caudal part of that region. The difference in the distribution of ENK- and putatively adrenergic LC-projecting cells in the PGi suggests neurochemical topography for LC-projecting neurons within the $\mathrm{PGi}$.

With respect to the PrII, previous studies have indicated that this nucleus may provide a potent GABAergic input to $\mathrm{LC}$ (Ennis and Aston-Iones, 1989a,b; Pieribone et al., 1990). Although we did not directly investigate this question, the high percentages of LC-projecting cells in PrH that were immunoreactive for ENK (56\%), or for GABA (70\%; Pieribone et al., 1990), suggest the possibility of coexistence for the two neurotransmitters in $\mathrm{PrH}$ neurons projecting to $\mathrm{LC}$. A definitive answer on the proportion of colocalization of ENK, GABA, and adrenaline in LC-projecting neurons of the rostral medulla requires further investigation.

\section{Functional significance}

The substantial innervation of the LC by ENK-ir fibers may indicate a role for the $\mathrm{LC}$ in opioid-induced analgesia. However, previous studies have produced conflicting evidence in this regard. Lesions of the LC or its projections have been reported to potentiate (Sawynok and Reid, 1987) or attenuate (Kostowski et al., 1978; Bodnar et al., 1990) morphine-produced analgesia. Electrical or glutamate stimulation of LC has been found to induce analgesia (Margalit and Segal, 1979; Jones and Gebhart, 1986,1988 ), but similar results have been obtained with morphine injection into the $\mathrm{LC}$, which would be expected to inhibit these cells (Jones and Gebhart, 1988; Bodnar et al., 1990). The possible role of opioids in the LC in mediation of analgesia requires further elucidation.

Recent physiologic studies have shown that the PrH provides an inhibitory synaptic input to the $\mathrm{LC}$, while the $\mathrm{PGi}$ provides both excitatory and inhibitory inputs to LC neurons (Ennis and Aston-Jones, 1988, 1989b; Astier and Aston-Jones, 1989; Aston-Jones et al., 1992). Given that opioid effects on LC neurons are inhibitory (North and Williams, 1985; Aghajanian and Wang, 1987; Christie et al., 1987; Williams et al., 1987), medullary enkephalinergic inputs would appear to be possible candidates for the mediation of PrH- and PGi-evoked inhibition of LC neurons. However, opioid antagonists have not been found 
to affect either PrH- or PGi-evoked inhibition of $\mathrm{LC}$ neurons (Ennis and Aston-Jones, 1988, 1989a,b; Aston-Jones et al., 1992). Similarly, there have been no reports of opioid-mediated synaptic events in LC neurons in in vitro slice studies (Aston-Jones et al., 1990). Naloxone-reversible inhibition of neurons in the LC of cat has been reported following stimulation of the arcuate nucleus (Strahlendorf et al., 1980, 1981), but the uncertain neurochemical identity of neurons recorded in cat LC make it difficult to interpret those results in terms of noradrenergic neurons. In addition, arcuate neurons do not project to rat $\mathrm{LC}$ (Foote et al., 1983; Aston-Jones et al., 1986, 1990), so these results may be species specific. Thus, although a very high proportion of LC-projecting cells in the rostral medulla appear to contain ENK, opioid influences on LC neurons are still obscure. The sparsity of effects reported for endogenous opioid inputs is in sharp contrast to the potent inhibitory effects induced by exogenously administcred opiates on LC neurons (North and Williams, 1985; Aghajanian and Wang, 1987; Christie et al., 1987; Williams et al., 1987). This discrepancy could be explained if enkephalin release only occurred under conditions or stimulus frequencies that have not been mimicked in the laboratory. Indeed, only few reports have appeared concerning opiate effects on LC activity in unanesthetized behaving animals. This could be significant, as it has been shown that the physiological characteristics of noradrenergic LC neurons differ in anesthetized and unanesthetized rats (Aston-Jones and Bloom, $1981 \mathrm{a}, \mathrm{b}$; Aston-Jones, 1985; Valentino and Wehby, 1988).

A recent study in the freely moving cat (Abercrombie and Jacobs, 1988) found that intravenous naloxone potentiated the increase in LC activity as well as signs of distress in response to stress, but in a resting, nonstressful, condition naloxone did not alter LC activity. Those results suggest that endogenous opioid inputs to LC, perhaps enkephalinergic, are not tonically active during resting conditions but may become active during stressful conditions to exert a moderating effect upon the activity of LC neurons. This is consistent with previous reports finding that opioid antagonists and agents that inhibit enkephalinase activity have no effect by themselves on LC neurons (Williams et al., 1987). Tanaka and colleagues have found that the increase in NE turnover in rat LC and its terminal areas induced by immobilization stress were attenuated by either morphine (Tanaka et al., 1983) or met-ENK (Tanaka et al., 1989), and were enhanced by pretreatment with the opioid antagonist naloxone (Tanaka et al., 1988, 1990). Thus, it seems possible that in different species opioid innervation of LC neurons may be most active during stressful conditions, implying a role for these inputs in stress responses. The present finding that strong ENKir inputs to LC originate from the rostral medulla is consistent with this possibility, as ncurons in these areas, especially the ventrolateral medulla, have been associated with visceral and autonomic systems that are involved in stress responses. Additional studies, including recording LC and medullary neurons during stress, are needed to test this possibility.

\section{References}

Abercrombie ED, Jacobs BL (1988) Systemic naloxone administration potentiates locus cocrulcus noradrencrgic ncuronal activity under stressful but not non-stressful conditions. Brain Res 441:362-366.

Aghajanian GK (1978) Tolerance of locus coeruleus neurons to morphine and suppression of withdrawal response by clonidine. Nature 276:186-188.
Aghajanian GK, Wang YY (1987) Common alpha 2- and opiate effector mechanisms in the locus coeruleus: intracellular studies in brain slices. Neuropharmacology 26:793-799.

Akil H, Watson SJ, Young E, Lewis ME, Khachaturian H, Walker JM (1984) Endogenous opioids: biology and functions. Annu Rev Neurosci 7:223-255.

Andrezik JA, Chan-Palay V, Palay SL (1981) The nucleus paragigantocellularis lateralis in the rat. Conformation and cytology. Anat Embryol 161:355-371.

Arbilla S, Langer SZ (1978) Morphine and $\beta$-endorphin inhibit release of noradrenaline from cerebral cortex but not of dopamine from rat striatum. Nature 271:559-561.

Astier B, Aston-Jones G (1989) Electrophysiological evidence for medullary adrenergic inhibition of rat locus coeruleus. Soc Neurosci Abstr 15:1012.

Astier B, Kitahama K, Denoroy L, Jouvet M, Renaud B (1987) Immunohistochemical evidence for the adrenergic medullary longitudinal bundle as a major ascending pathway to the locus coeruleus. Neuroscience 74:132-138.

Aston-Jones G (1985) Behavioral functions of locus coeruleus derived from cellular attributes. Physiol Psychology 13:118-126.

Aston-Jones G, Bloom FE (1981a) Activity of norepinephrine-containing locus coeruleus neurons in behaving rats anticipates fluctuations in the sleep-waking cycle. J Neurosci 1:876-886.

Aston-Jones G, Bloom FE (1981b) Norepinephrine-containing locus coeruleus neurons in behaving rats exhibit pronounced responses to non-noxious environmental stimuli. J Neurosci 1:887-900.

Aston-JonesG,EnnisM,PieriboneVA,NickellWT,ShipleyMT (1986)The brain nucleus locus coeruleus: restricted afferent control of a broad efferent network. Science 234:734-737.

Aston-Jones G, Shipley MT, Ennis M, Williams JT, Pieribone VA (1990) Restricted afferent control of locus coeruleus neurons revealed by anatomic, physiologic and pharmacologic studies. In: The pharmacology of noradrenaline in the central nervous system (Marsden CA, Heal DJ, eds), pp 187-247. Oxford: Oxford UP.

Aston-Jones G, Shipley MT, Chouvet G, Ennis M, Van Bockstaele E, Pieribone V, Shiekhattar R, Akaoka H, Drolet G, Astier B, Charléty P, Valentino R, Williams JT (1991) Afferent regulation of locus coeruleus neurons: anatomy, physiology and pharmacology. Prog Brain Res 88:47-75.

Aston-Jones G, Astier B, Ennis M (1992) Inhibition of noradrenergic locus coeruleus neurons by $\mathrm{Cl}$ adrenergic cells in the rostral ventral medulla. Neuroscience 48:371-382.

Atweh SF, Kuhar MJ (1977) Autoradiographic localization of opiate receptors in rat brain. II. The brainstem. Brain Res 129:1-12.

Basbaum AI, Menetrey D (1987) Wheat germ agglutinin-apoHRP gold: a new retrograde tracer for light- and electron-microscopic single- and double-label studies. J Comp Neurol 261:306-318.

Bird SJ, Kuhar MJ (1977) Iontophoretic applications of opiates to the locus coeruleus. Brain Res 122:523-533.

Bloom FE, Battenberg E, Rossier J, Ling N, Guillemin R (1978) Neurons containing $\beta$-endorphin in rat brain exist separately from those containing enkephalin: immunocytochemical studies. Proc Natl Acad Sci USA 75:1591-1595.

Bodnar RJ, Paul D, Rosenblum M, Liu L, Pasternak GW (1990) Blockade of morphine analgesia by both pertussis and cholera toxins in the periaqueductal gray and locus coeruleus. Brain Res 529:324-328.

Cassini P, Ho RH, Martin GF (1989) The brainstem origin of enkephalin- and substance-P-like immunoreactive axons in the spinal cord of the North American opossum. Brain Behav Evol 34:212-222.

Ceccatelli S, Millhorn DE, Hokfelt T, Goldstein M (1989) Evidence for the occurrence of an enkephalin-like peptide in adrenaline and noradrenaline neurons of the rat medulla oblongata. Exp Brain Res 74:631-640.

Charnay Y, Léger L, Dray F, Berod A, Jouvet M, Pujol J-F, Dubois PM (1982) Evidence for the presence of enkephalin in catecholaminergic neurons of the cat locus coeruleus. Neurosci Lett 30:147151.

Christie MJ, Williams JT, North RA (1987) Cellular mechanisms of opioid tolerance: studies in single brain neurons. Mol Pharmacol 32: 633-638.

Comb M, Seeburg P, Adelman J, Eiden L, Herbert E (1982) Primary structure of the human met- and leu-enkephalin precursor and its mRNA. Nature 295:663-666.

Ennis M, Aston-Jones G (1988) Activation of locus coeruleus from 
nucleus paragigantocellularis: a new excitatory amino acid pathway in brain. J Neurosci 8:3644-3657.

Ennis M, Aston-Jones G (1989a) Potent inhibitory input to locus coeruleus from the nucleus prepositus hypoglossi. Brain Res Bull 22: 793-803.

Ennis M, Aston-Jones G (1989b) GABA-mediated inhibiton of locus coeruleus from the dorsomedial rostral medulla. J Neurosci 9:29732981.

Fallon JH, Leslic FM (1986) Distribution of dynorphin and enkephalin peptides in the rat brain. J Comp Neurol 249:293-336.

Finley JCW, Lindström P, Petrusz P (1981a) Immunohistochemical localization of $\beta$-endorphin-containing neurons in the rat brain. Neuroendocrinology 33:28-42.

Finley JCW, Maderdrut JL, Petrusz P (1981b) The immunocytochemical localization of enkephalin in the central nervous system of the rat. J Comp Neurol 198:541-565.

Foote SL, Bloom F, Aston-Jones G (1983) The nucleus locus coeruleus: new evidence of anatomical and physiological specificity. Physiol Rev 63:844-914.

Fu L, Shipley MT, Aston-Jones G (1989) Dendrites of rat locus coeruleus are asymmetrically distributed: immunocytochemical LM and EM studies. Soc Neurosci Abstr 15:1013.

Grzanna R, Molliver ME (1980) The locus coeruleus in the rat: an immunohistochemical delineation. Neuroscience 5:21-40.

Herz A (1984) Multiple endorphins as natural ligands of multiple opioid receptors. In: Central and peripheral endorphins: basic and clinical aspects (Müller E, Genazzani A, eds), pp 43-52. New York: Raven.

Ibuki T, Okamura H, Miyazaki M, Yanaihara N, Zimmerman EA, Ibata $Y$ (1989) Comparative distribution of three opioid systems in the lower brainstem of the monkey (Macaca fuscata). J Comp Neurol 279:445-456.

Johnson SM, Fleming WW (1990) Mechanisms of cellular adaptative sensitivity changes: applications to opioid tolerance and dependence. Pharmacol Rev 41:435-488.

Jones SL, Gebhart GF (1986) Characterization of coeruleospinal inhibition of the nociceptive tail-flick reflex in the rat: meditation by spinal $\alpha_{2}$-adrenoceptors. Brain Res 364:315-330.

Jones SL, Gebhart GF (1988) Inhibition of spinal nociceptive transmission from the midbrain, pons and medulla in the rat: activation of descending inhibition by morphine, glutamate and electrical stimulation. Brain Res 460:281-296.

Khachaturian H, Lewis ME, Watson SJ (1983) Enkephalin systems in the diencephalon and brainstem of the rat. J Comp Neurol 220: 310-320.

Kilpatrick D, Jones B, Kojima K, Udenfriend S (1981) Identification of the octapeptide [met]-enkephalin-Arg ${ }^{6}-\mathrm{Gly}^{7}-\mathrm{Leu}^{8}$ in extracts of bovine adrenal medulla. Biochem Biophys Res Commun 103:698-705.

Kostowski W, Jerlicz M, Bidzinski A, Hauptmann M (1978) Reduced analgesic effects of morphine after bilateral lesions of the locus coeruleus in rats. Pol J Pharmacol Pharm 30:9-53.

Lewis R, Stern A (1983) Biosynthesis of the enkephalins and enkephalin-containing polypeptides. Annu Rev Pharmacol Toxicol 23:353372 .

Margalit D, Segal M (1979) A pharmacologic study of analgesia produced by stimulation of the nucleus locus coeruleus. Psychopharmacology 62:169-173.

McFadzean I, Lacey MC, Hill RG, Henderson G (1987) Kappa opioid receptor activation depresses excitatory synaptic input to rat locus coeruleus neurons in vitro. Neuroscience 20:231-239.

Ménétrey D (1985) Retrograde tracing of neural pathways with a protein-gold complex. I. Light microscopic detection after silver intensification. Histochemistry 83:391-395.

Ménétrey D, Basbaum AI (1987) The distribution of substance P-, enkephalin- and dynorphin-immunorcactive ncurons in the medulla of the rat and their contribution to bulbospinal pathways. Neuroscience 23:173-187.

Montel H, Starke K, Weber F (1974) Influence of morphine and naloxone on the release of noradrenaline from rat brain cortex slices. Naunyn Schmiedebergs Arch Pharmacol 283:357-369.

Murakami S, Okamura H, Yanaihara C, Yanaihara N, Ibata Y (1987) Immunocytochemical distribution of met-enkephalin-Arg ${ }^{6}-\mathrm{Gly}^{7}-\mathrm{Leu}^{8}$ in the rat lower brainstem. J Comp Neurol 261:193-208.

Murakami S, Okamura H, Pelletier G, Ibata Y (1989) Differential colocalization of neuropeptide $\mathrm{Y}$ - and methionine-enkephalin- $\mathrm{Arg}^{6}$ -
Gly'-Leu ${ }^{8}$-like immunoreactivity in catacholaminergic neurons in the rat brain stem. J Comp Neurol 281:532-544.

North RA, Williams JT (1985) On the potassium conductance increase by opioids in rat locus coeruleus neurons. J Physiol (Lond) 364:265280.

Paxinos G, Watson C (1986) The rat brain in stereotaxic coordinates. New York: Academic.

Pert CB, Kuhar MJ, Snyder SH (1975) Autoradiographic localization of the opiate receptor in rat brain. Life Sci 16:1849-1854.

Petrusz P, Merchenthaler I, Maderdrut JL (1985) Distribution of enkephalin-containing neurons in the central nervous system. In: Handbook of chemical neuroanatomy (Björklund $A$, Hökfelt $T$, eds), pp 273-334. New York: Elsevier.

Pickel VM, Joh TH, Reis DJ, Leeman SE, Miller RJ (1979) Electron microscopic localization of substance $P$ and enkephalin in axon terminals related to dendrites of catecholaminergic neurons. Brain Res 160:387-400.

Pieribone VA, Aston-Jones G (1991) Adrenergic innervation of the rat nucleus locus coeruleus arises predominantly from the $\mathrm{Cl}$ adrenergic cell group in the rostral medulla. Neurosci Lett 41:525-542.

Pieribone VA, Aston-Jones G, Bohn MC (1988) Adrenergic and nonadrenergic neurons of the $\mathrm{Cl}$ and $\mathrm{C} 3$ areas project to locus coeruleus: a fluorescent double labeling study. Neuroscience 85:297-303.

Pieribone VA, Shipley MT, Ennis M, Aston-Jones G (1990) Anatomic evidence for GABAergic afferents to the rat locus coeruleus in the dorsal medial medulla: an immunocytochemical and retrograde transport study. Soc Neurosci Abstr 16:300.

Reddy VK, Fung SJ, Zhuo H, Barnes CD (1990) Localization of enkephalin neurons in the dorsolateral pontine tegmentum projecting to the spinal cord of the cat. J Comp Neurol 291:195-202.

Sar M, Stumpf WE, Miller RJ, Chang K-J, Cuatrecasas P (1978) Immunohistochemical localization of enkephalin in rat brain and spinal cord. J Comp Neurol 182:17-38.

Sasek CA, Helke CJ (1989) Enkephalin-immunoreactive neuronal projections from the medulla oblongata to the intermediolateral cell column: relationship to substance P-immunoreactive neurons. J Comp Ncurol 287:484-494.

Sawynok J, Reid A (1987) Effect of 6-hydroxydopamine-induced lesions to ascending and descending noradrenergic pathways on morphine analgesia. Brain Res 419:156-165.

Shipley MT, Harris G, Williams J, Van Bockstaele EJ, Aston-Jones G, Ennis M (1990) Asymmetric orientation of locus coeruleus (LC) dendrites in the pericoeruleus region: In vitro slice, biocytin-filled LC neurons. Soc Neurosci Abstr 16:1177.

Simantov R, Kuhar MJ, Uhl GR, Snyder SH (1977) Opioid peptide enkephalin: immunohistochemical mapping in rat central nervous system. Proc Natl Acad Sci USA 74:2167-2171.

Strahlendorf HK, Strahlendorf JC, Barnes CD (1980) Endorphin-mediated inhibition of locus coeruleus neurons. Brain Res 191:284-288.

Strahlendorf HK, Strahlendorf JC, Barnes CD (1981) Stimulation of hypothalamic arcuate nucleus inhibits locus coeruleus unit activity: evidence for endorphin mediation. Prog Clin Biol Res 68:161-169.

Swanson LW (1976) The locus coeruelus: a cytoarchitectonic, Golgi and immunohistochemical study in the albino rat. Brain Res 110:3956.

Tanaka M, Kohno Y, Tsuda A, Nakagawa R, Ida Y, Iimori K, Hoaki $Y$, Nagasaki N (1983) Differential effects of morphine on noradrenaline release in brain regions of stressed and non-stressed rats. Brain Res 275:105-115.

Tanaka M, Ida Y, Tsuda A (1988) Naloxone, given before but not after stress exposure, enhances stress-induced increases in regional brain noradrenaline release. Pharmacol Biochem Behav 29:613-616.

Tanaka M, Ida Y, Tsuda A, Tsujimaru S, Shirao I, Oguchi M (1989) Met-enkephalin, injected during the early phase of stress, attenuates stress-induced increases in noradrenaline release in rat brain regions. Pharmacol Biochem Behav 32:791-795.

Tanaka M, Tsuda A, Yokoo H, Yoshida M, Ida Y, Nishimura H (1990) Involvement of the brain noradrenaline system in emotional changes caused by stress in rats. Ann NY Acad Sci 597:159-174.

Tempel A, Zukin RS (1987) Neuroanatomical patterns of the $\mu, \delta$ and $\kappa$ opioid receptors of rat brain as determined by quantitative in vitro autoradiography. Proc Natl Acad Sci USA 84:4308-4312.

Uhl GR, Goodman RR, Kuhar MJ, Childers SR, Snyder SH (1979) Immunohistochemical mapping of enkephalin containing cell bodies, 
fibers and nerve terminals in the brainstem of the rat. Brain Res 166: $75-94$.

Valentino RJ, Wehby RG (1988) Morphine effects on locus coeruleus neurons are dependent on the state of arousal and availability of external stimuli: studies in anesthetized and unanesthetized rats. J Pharmacol Exp Ther 244:1178-1186.

Van Bockstaele E, Pieribone V, Aston-Jones G (1989) Diverse afferents converge on the nucleus paragigantocellularis in the rat ventrolateral medulla: retrograde and anterograde tracing studies. J Comp Neurol 290:561-584.

Van Bockstaele EJ, Aston-Jones G (in press) Collateralized projections from neurons in the rostral medulla to the nucleus locus coeruleus, the nucleus of the solitary tract and the periaqueductal gray. Neuroscience, in press.

Watson SJ, Khachaturian H, Akil H, Coy DH, Goldstein A (1982) Comparison of the distribution of dynorphin systems and enkephalin systems in brain. Science 218:1134-1136.
Weber E, Roth KA, Evans CJ, Chang J-K, Barchas JD (1982) Immunohistochemical localization of dynorphin $(1-8)$ in hypothalamic magnocellular neurons: evidence for absence of proenkephalin. Life Sci 31:1761-1764.

Williams JT, Christie MJ, North RA, Roques BP (1987) Potentiation of enkephalin action by peptidase inhibitors in rat locus coeruleus in vitro. J Pharmacol Exp Ther 243:397-401.

Williams RG, Dockray GJ (1983) Distribution of enkephalin-related peptides in rat brain: immunohistochemical studies using antisera to met-enkephalin and met-enkephalin $\mathrm{Arg}^{6} \mathrm{Phe}^{7}$. Neuroscience 9:563586.

Young W, Bird SJ, Kuhar MJ (1977) Iontophoresis of methionineenkephalin in the locus coeruleus area. Brain Res 129:366-370.

Zamir N, Weber E, Palkovits M, Brownstein M (1984) Differential processing of prodynorphin and proenkephalin in specific regions of the rat. Proc Natl Acad Sci USA 81:6886-6889. 